Araştırma Makalesi - Research Article

\title{
Yapay Sinir Ăgları ve Regresyon Yöntemleri ile Geri Esneme Tahmini
}

\author{
Süleyman KILIÇ ${ }^{1^{*}}$
}

Geliş / Received: 13/09/2019

Revize / Revised: 21/11/2019

Kabul / Accepted: 28/11/2019

ÖZ

Geri esneme, imalat süreçlerinde karşılaşılan problemlerin başında gelmektedir. Geri esneme olayının giderilmesinde deneme yanılma gibi maliyetli yöntemler kullanılmaktadır. Günümüz dünyasında bilgisayar teknolojisinin gelişmesiyle beraber bütün alanlarda bilgisayar ve bilgisayar programlarının kullanımı yaygınlaşmıştır. Yapay zekâ teknolojisi ile dışarıdan sisteme bilinen veriler girilerek, sistemin bilinmeyen durumları tahmin etmesi beklenmektedir. Bu çalışma kapsamında, Yapay Sinir Ağları (YSA) ve Regresyon yöntemi kullanılarak geri esneme tahmini yapılmıştır. Farklı parametrelerin etkisini görebilmek için farklı YSA modelleri oluşturulmuş ve birbiriyle kıyaslanmıştır. Yapılan çalışmalar sonucunda, YSA modellerinde uygun parametre seçiminin oldukça önemli olduğu görülmüştür. YSA model sonuçlarının, Regresyon model sonuçlarından daha başarılı tahminler yaptığı görülmüştür.

Anahtar Kelimeler- Yapay Sinir Ağları, Regresyon, AA7075, Yaşlandırma, Geri Esneme

1*Sorumlu yazar iletişim: suleymankilic@gmail.com (https://orcid.org/0000-0002-1681-9403)

Makine Mühendisliği Bölümü, Kırșehir Ahi Evran Üniversitesi, Bağbaşı Mah. Sahir Kurutluoğlu Cad. No: 100 KIRŞEHIR 


\title{
Estimation of Springback with Artificial Neural Networks and Regression Methods
}

\begin{abstract}
Springback is one of the problems encountered in manufacturing processes. Cost-effective methods such as trial and error are used in eliminating the springback process. With the development of computer technology in today's world, the use of computer and computer programs has become widespread in all fields. It is expected that the system can predict unknown situations by entering known data from the external system with artificial intelligence technology. In this study, springback estimation is made by using Artificial Neural Networks (ANN) and Regression method. In order to see the effect of different parameters, different ANN models have been created and compared with each other. As a result of the studies, it is seen that the selection of appropriate parameters is very important in ANN models. It is seen that ANN model results make more successful predictions than Regression model results.
\end{abstract}

Keywords-Artificial Neural Networks, Regression, AA7075, Aging, Springback 


\section{Gİiș}

Gelişen bilgisayar sistemleri sayesinde, günlük hayatımızda kullandığımız cihazlardan, fabrikalardaki cihazlara kadar tüm sektörlerde gelişmeler olmaktadır. Özellikle yapay zekâ teknolojisi hayatımızın her alanında yaygınlaşmaya başlamıştır. İlk olarak 1950'li yıllarda ortaya çıkan bu terim, günümüze kadarki süreçte birçok yeni sistemlerin ortaya çıkmasına neden olmuştur [1]. Bu kavramın temelinde, öğrenme fonksiyonu olan bir sistem yer almaktadır. Bu sistemin çalışma yapısı; bilinen veriler ile sistemin öğrenmesi sağlama ve bilinmeyen veriler için sistemden sonuç değerlerinin talep edilmesinden oluşmaktadır.

Araştırmacılar tarafından yapay zekâ konusunda neredeyse bütün alanlarda çalışmalar yapılmaktadır. Hamzaçebi ve Kutay [2], 2004 yılında yaptıkları çalışma ile Türkiye'nin 2010 yılındaki elektrik enerjisi tüketimini tahmin etmişlerdir. Ataseven [3], bir şirketin ürün satış rakamlarının tahmin edilmesinde kullanmıştır. Uğur ve Kınacı [4], yapay sinir ağları yöntemini kullanarak web sayfalarının sınıflandırılması konusunda çalışmışlardır. Kutlu ve Badur [5], yapay sinir ağları yöntemiyle borsa endeksinin tahmini üzerine bir çalışma yürütmüşlerdir. Yıldıran ve Kandemir [6], Yapay sinir ağları yöntemini kullanarak yağış miktarı tahmini yapmışlardır. Güngör [7], güneş panellerinde verim artırılması işleminde PNO, BM ve YSA algoritmalarını kullanarak karşılaştırma çalışması yapmıştır.

İmalat süreçlerinde de, yapay zekâ ile ilgili çalışmalar artarak devam etmektedir. Kubat ve Kiraz [8], yapay zeka kullanarak sanal laboratuvar tasarımında çekme testinin modellemesi üzerine çalışmışlardır. Aynı malzemeye ait farklı hızlarda elde edilen verileri kullanarak, ara değerlerde çekme deneyi yapmadan, değerlerin elde edilmesini sağlamışlardır. Toktaş ve Aktürk [9], yapay sinir ağları tabanlı silindirik düz dişli çark tasarımı üzerine çalışmışlardır. Dişli çarkların tasarımında kullanılan analitik denklemler yerine, YSA tabanlı sistemlerin kullanımının daha başarılı ve hata oranının düşük olduğunu göstermişlerdir. Ergür [10], aşındırıcı su jetinin teorik analizi ve YSA yöntemiyle modelleme işlemi üzerine çalışmıştır. YSA yöntemiyle başarılı sonuçlar alındığını göstermiştir. Bilgiç ve arkadaşları [11], deneysel bir organik Rankine çeviriminde YSA yardımıyla güç tahmini üzerine çalışmışlardır. YSA ile yapılan tahminlerin gerçek sonuçlara daha yakın olduğu vurgulanmıştır.

Eğme işlemi, imalat sanayinde sıklıkla kullanılan bir sac şekillendirme yöntemidir. Uygulanan eğme kuvveti altında malzeme plastik olarak şekil değiştirir. Malzemenin plastik şekil değiştirmesinden sonra zımba kuvvetinin ortadan kalkmasıyla malzemenin bir miktar eğme açısı değişmektedir. Bu açı değişimine de geri esneme denilmektedir. Geri esneme olayı, imalat sanayinde karşılaşılan problemlerin başında gelmekte ve konu hakkında araştırmalar yapılmaktadır [12-15]. Inamdar ve arkadaşları [16], geri esnemenin tahmininde YSA kullanımını incelemişlerdir. Makine üzerinde bükme işlemi esnasında gerçek zamanlı olarak, zımba mesafesinin YSA yardımıyla hesaplanmasını ve geri esnemeyi kabul edilebilir sınırların içine çekmeyi hedeflemişlerdir. Geliştirmiş oldukları YSA kodu ile zımba mesafesi otomatik olarak ayarlanmaktadır. Önerdikleri model ile analitik geri esneme hesabından daha iyi sonuçlar elde etmişlerdir. Kazan ve arkadaşları [17], sonlu elemanlar analiz verilerine dayanarak, yapay sinir ağları ile geri esneme tahmin modeli oluşturmuşlardır. İyi eğitilmiş bir YSA modelinin, hızlı ve tutarlı sonuçlar sağladığı vurgulanmıştır. Çalışmada sundukları yöntemin pratik ve hızlı bir yaklaşım olduğunu ifade etmişlerdir. Bozdemir ve Gölcü [18], V kalıpta bükme işleminde YSA tekniği ile geri esneme tahminini incelemişlerdir. Giriş parametreleri olarak malzeme, bükme açısı ve r/t oranlarını kullanmışlardır. Bükme işlemi sonucu oluşan geri esnemenin tahmininde, YSA yönteminin uygun ve hassas sonuçlar verdiği gösterilmiştir. Liu ve arkadaşları [19], geri esneme olayında YSA ve genetik algoritma optimizasyon tekniklerinin birlikte kullanıldığında, bu yöntemin YSA yöntemine göre daha başarılı tahminler yaptığını göstermişlerdir. Zhang ve arkadaşları [20], YSA yöntemi ile geri esneme tahmini yapmışlardır. Çalışmalarında, zımbanın eğme noktası ve zımba derinliğini giriş parametreleri olarak kullanmışlardır. Eğitim verisi sayısının, tahmin doğruluğu üzerinde etkili olduğu vurgulanmıştır.

$\mathrm{Bu}$ çalışma kapsamında, imalat süreçlerinde en önemli sorunlardan biri olan geri esneme miktarının tahmini için YSA ve Regresyon modelleri kullanılmış ve bu modellerin karşılaştırması yapılmıştır. Geri esneme üzerinde bir çok parametre etkilidir. Bu çalışmada, literatürden farklı olarak yaşlandırma işleminde, geri esnemenin YSA ile tahmini incelenmiştir. Bu sayede, yaşlandırma işlemi uygulanmayan parametrelerdeki geri esneme değerleri elde edilmiş olacaktır. Yaşlandırma işleminde etkisi bulunan ön gerinme miktarı, akma mukavemeti, çekme mukavemeti, yaşlandırma sıcaklığı ve süresi gibi etkenler giriş parametreleri, geri esneme 
ise çıkış parametresi olarak kullanılmıştır. Malzeme seçiminde ise havacılık endüstrisinde önemli bir malzeme olan 7075 serisi alüminyum alaşımı tercih edilmiştir.

\section{MALZEME VE YÖNTEM}

2 mm kalınlığında 7075-T6 malzemesine farklı sıcaklık ve sürelerde yaşlandırma işlemi uygulanarak mekanik özelliklerin değişimi daha önceki çalışmamızda incelenmişti [21]. Bu yapılan çalışmada ise, yayınlanan çalışmadaki deneysel veriler kullanılmıştır. Farklı yaşlandırma sıcaklıklarında $\left(120{ }^{\circ} \mathrm{C}, 160{ }^{\circ} \mathrm{C}\right.$ ve $\left.200{ }^{\circ} \mathrm{C}\right)$ ve farklı yaşlandırma srelerinde $(30,90,180,1080$ ve 2880 dakika) çekme ve eğme deneyleri yapılmıştır. Aynı zamanda, malzemeye uygulanan ön gerinmenin etkisini inceleyebilmek için farklı numunelere \%4 oranında ön gerinme uygulanmış ve aynı parametrelerde yaşlandırma işlemi uygulanmıştır. Malzemenin farklı yaşlandırma koşulları altında akma mukavemeti, çekme mukavemeti, geri esneme miktarları ile ön gerinme uygulanması durumundaki deneysel değerleri veri seti olarak kullanılmıştır. Eğitim verileri, ön gerinme uygulanmayan ve ön gerinme uygulanan deneyler eşit olacak şekilde rastgele seçilmiştir.

$\mathrm{Bu}$ deneysel veri setleri ile Yapay Sinir Ağları (YSA) ve Regresyon yöntemleri kullanılarak geri esneme tahminleri yapılmıştır. YSA; verilen olaylar arasındaki ilişkiyi öğrenerek, daha sonra hiç görmediği durumlar hakkında öğrendiği bilgilerden yola çıkarak karar veren sistemlerdir. Bu çalışma kapsamında farklı tiplerde YSA modelleri oluşturularak, bunların etkisi de incelenmiştir. Bütün modellerde ön gerinme, yaşlandırma sıcaklığı, yaşlandırma süresi, akma mukavemeti, çekme mukavemeti parametreleri sisteme veri girişi olarak kullanılmıştır. Şekil 1.'de tek katmanlı, Şekil 2.'de iki katmanlı ve Şekil 3.’te üç katmanlı şematik YSA modelleri verilmiştir. Normalde, bir ara katman kullanarak problemler çözülebilmektedir. Fakat bu çalışmada, ara katman sayısının etkisini belirleyebilmek için farklı ara katmanlar denenmiştir.

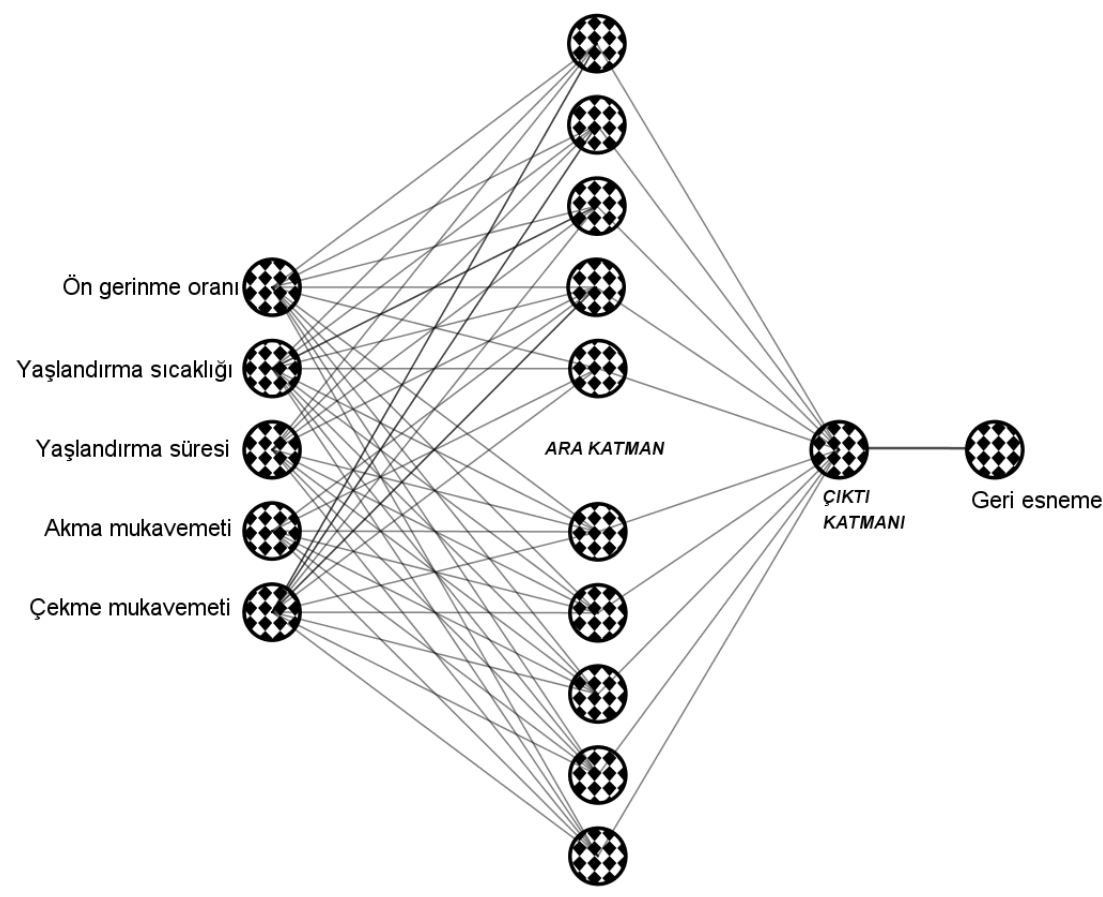

Şekil 1. Tek katmanlı YSA modeli 


\begin{tabular}{|c|c|c|}
\hline & $\begin{array}{l}\text { BŞEÜ Fen Bilimleri Dergisi } \\
6(2), 433-446,2019\end{array}$ & $\begin{array}{l}\text { BSEU Journal of Science } \\
\text { DOI: } 10.35193 / \text { bseufbd.620010 }\end{array}$ \\
\hline $\begin{array}{l}\text { BiLECIK SEYHEDEBAL } \\
\text { UNIVERSITES }\end{array}$ & & e-ISSN: $2458-7575$ (http://dergipark.gov.tr/bseufbd) \\
\hline
\end{tabular}

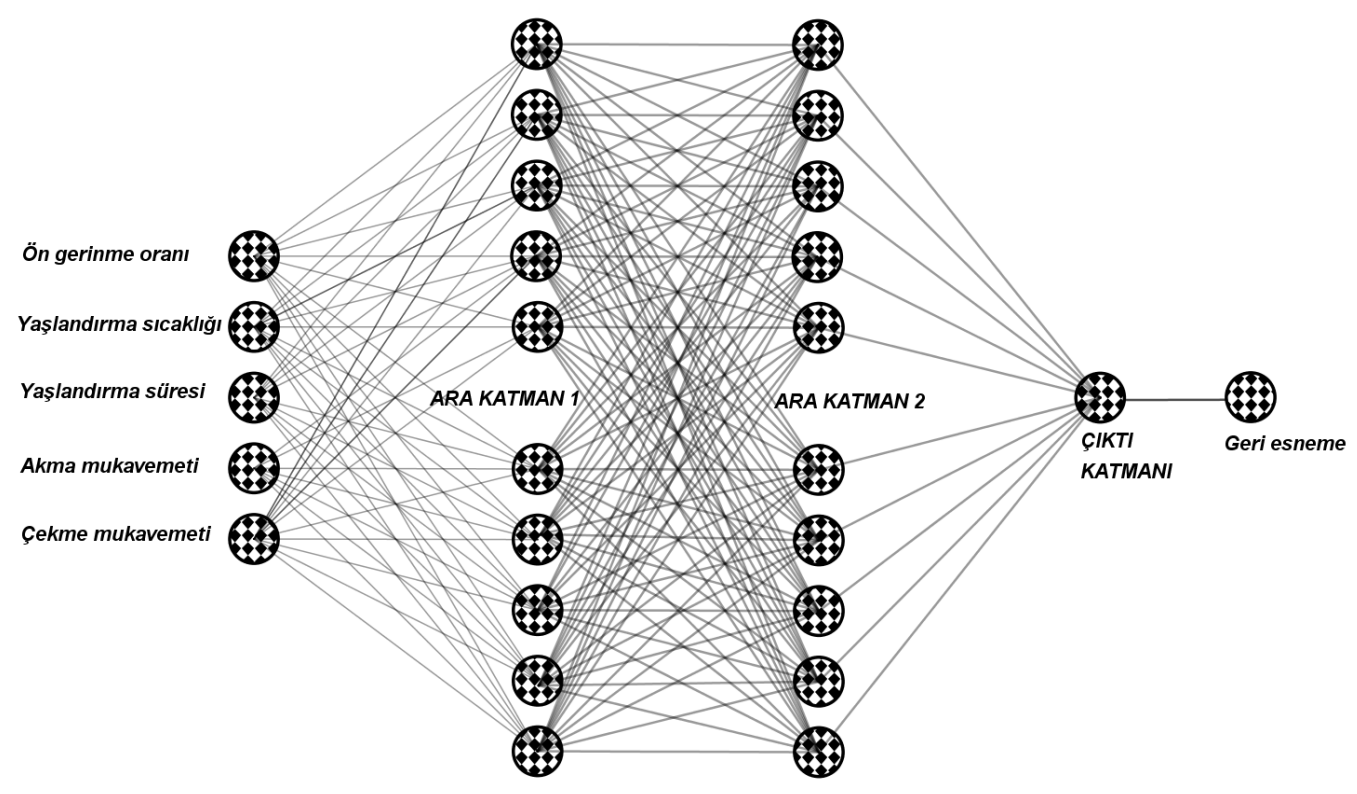

Şekil 2. İki katmanlı YSA modeli

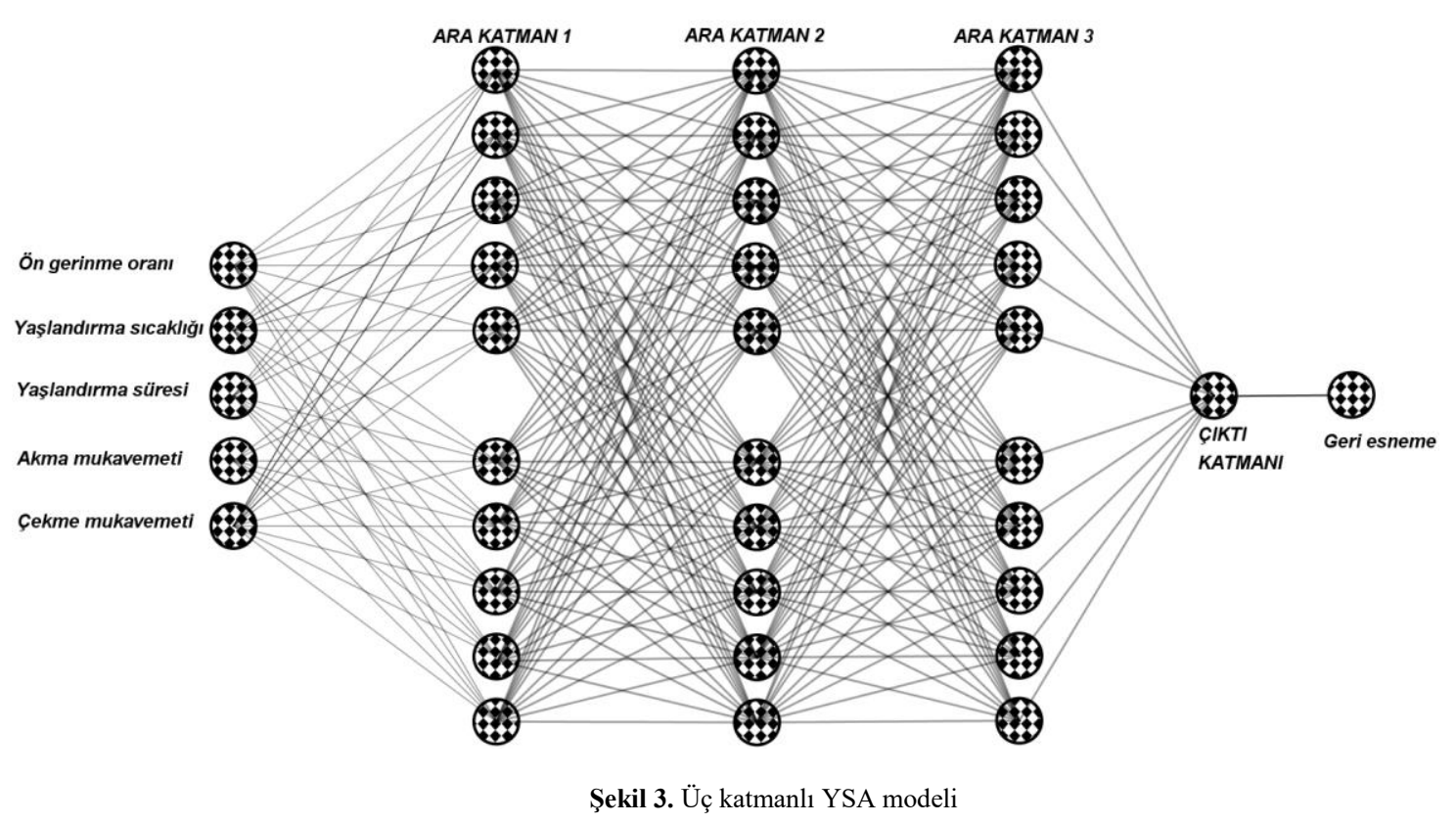

III. BULGULAR VE TARTIŞMA

A. Yapay Sinir Ağları (YSA)

Öğrenme algoritması olarak; ileri beslemeli ağ, öğrenme fonksiyonu olarak; Levenberg-Marquardt algoritması kullanılmıştır. Levenberg-Marquardt algoritmasında ikinci dereceden türevler kullanıldığından, yapay sinir ağlarının eğitiminde hız ve kararlılık sağladığı bilinmektedir [22]. Öğrenme işleminde hata oranı 1e08, deneme sayısı ise, 1000 olarak seçilmiştir. Elimizdeki deneysel veri sayısı 30'dur. Şekil 5-9 arasındaki grafiklerde 18 eğitim datası, Şekil 10-12'de ise, 24 tane eğitim datası rastgele seçilerek kullanılmıştır. Çalışma 
kapsamında; farklı gizli katman ve nöron sayısının etkisi de incelenmiştir. Bu doğrultuda Şekil 4.’te gösterildiği üzere gizli katmandaki nöron sayısı 10, 15 ve 20 seçilerek tahminler yaptırılmıştır. Bunlar genellikle belirli bir kural içermeyip, deneme yanılma yoluyla bulunmaktadır.

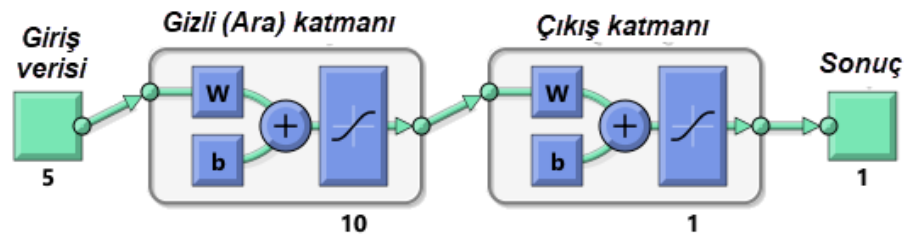

Şekil 4. Bir gizli katmanlı model yapısı

Şekil 5.'deki sonuçlar incelendiğinde, katmandaki nöron sayısının tahmin üzerindeki etkisi açıkça görülmektedir. Grafik üzerinde korelasyon katsayıları verilmiştir. 1 numaralı eşitlikte verilen ifade yardımıyla korelasyon katsayısı hesaplanmaktadır [23]. Korelasyon katsayısı (R) iki veri arasındaki ilişkiyi ifade etmektedir. Korelasyon katsayısının değerinin 1'e yakın olması, veriler arasındaki uyumu ifade etmektedir. 0,01-0,29 arasındaki değerler düşük düzeyde ilişki, 0,3-0,7 arasında orta düzeyde ilişkiyi, 0,71-0,99 değeri yüksek düzeyde ilişkiyi ifade etmektedir [24]. Burada en yakın sonucun 15 nöron ile elde edildiği görülmüştür. Denklemde $\bar{x}$ ve $\bar{y}$ örnek ortalama değerleri ifade etmektedir.

$$
\operatorname{Correl}(x, y)=\frac{\sum(x-\bar{x})(y-\bar{y})}{\sqrt{\sum(x-\bar{x})^{2} \sum(y-\bar{y})^{2}}}
$$

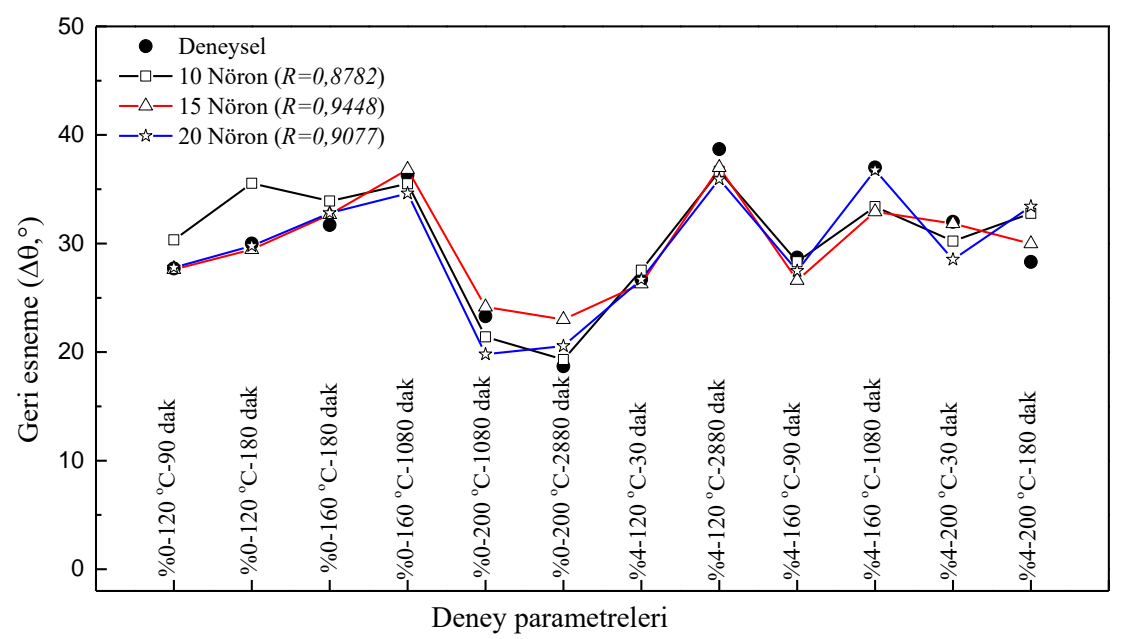

Şekil 5. Bir gizli katmanlı modelde nöron sayısın tahmin üzerindeki etkisi (18 eğitim verisi)

Şekil 6.'da, iki gizli katmanlı model yapısı görülmektedir. İlk modelde; birinci katmanda 20, ikinci katmanda ise 10 ağ, ikinci modelde ise; her katmanda 10'ar ağ kullanarak modeller oluşturulmuştur. (Model 1layer 1: 20 nöron, Layer 2: 10 nöron; Model 2- layer 1: 10 nöron, Layer 2: 10 nöron) 


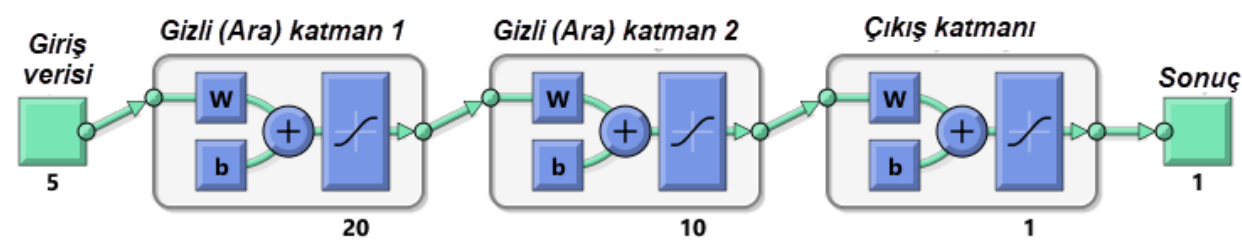

Şekil 6. İki gizli katmanlı model yapısı

Şekil 7.'de iki gizli katmanlı modelde nöron sayısının değişiminin, tahmin üzerindeki etkisi verilmiştir. Bu modelde korelasyon katsayıları incelendiğinde, Model 2'nin Model 1'e göre daha yakın sonuçlar verdiği görülmektedir. Model 1, bazı deneysel verileri daha yakın tahmin ettiği, aynı şekilde Model 2'nin de bazı deneysel verileri iyi tahmin ettiği görülmektedir. Bu durum için nöron sayılarının değiştirilerek denenmesi halinde, biraz daha yakın sonuçlar vereceği düşünülmektedir.

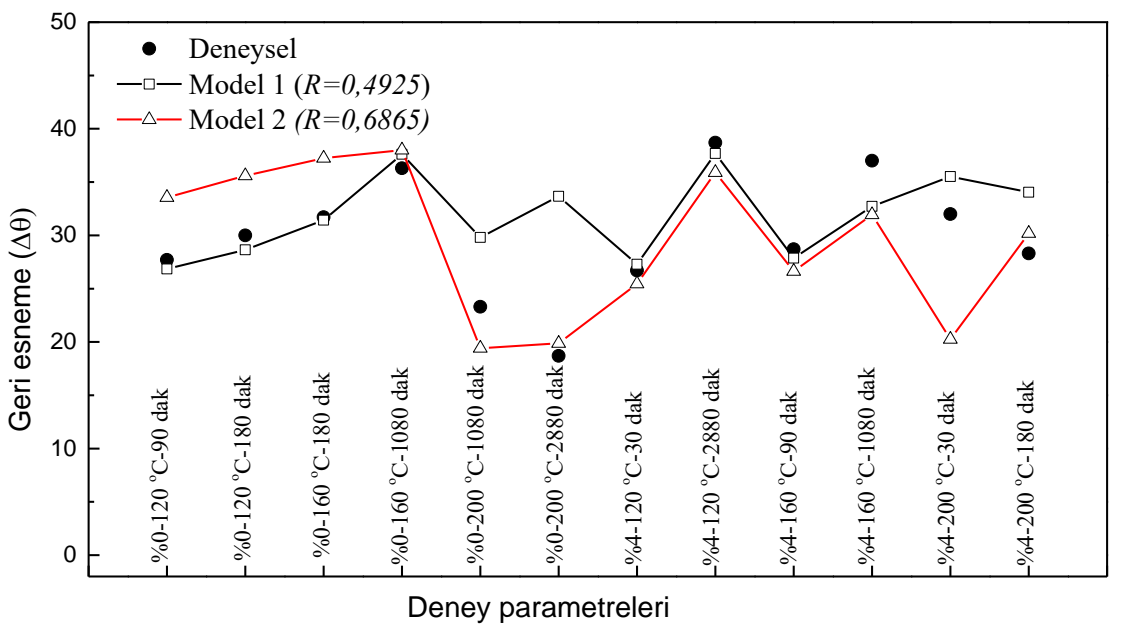

Şekil 7. İki gizli katmanlı modelde nöron sayısının tahmin üzerindeki etkisi (18 eğitim verisi)

Şekil 8.'de üç gizli katmanlı model yapısı görülmektedir. Her katmanda 10'ar ağ yapısı oluşturulmuştur. Şekil 9.'da, üç farklı katman kullanılarak elde edilen model tahmin sonucu görülmektedir. Korelasyon katsayısının yine 1 değerine yakın olması, veriler arasındaki ilişkinin yüksek olduğunu ifade etmektedir.

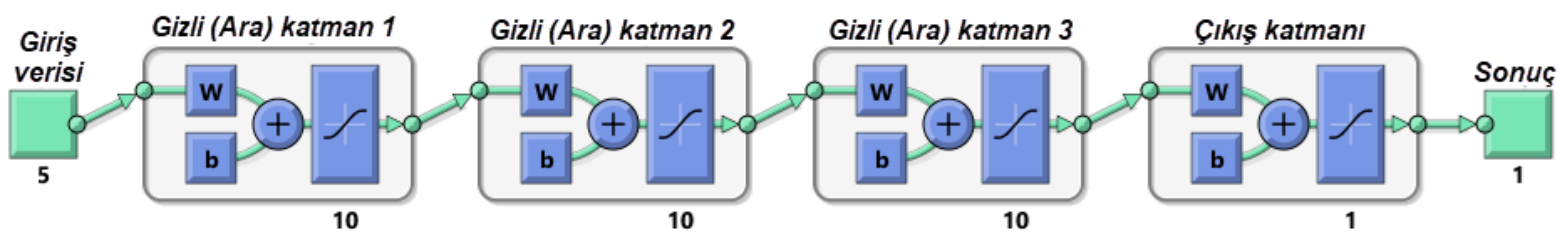

Şekil 8. Üç gizli katmanlı model yapısı 


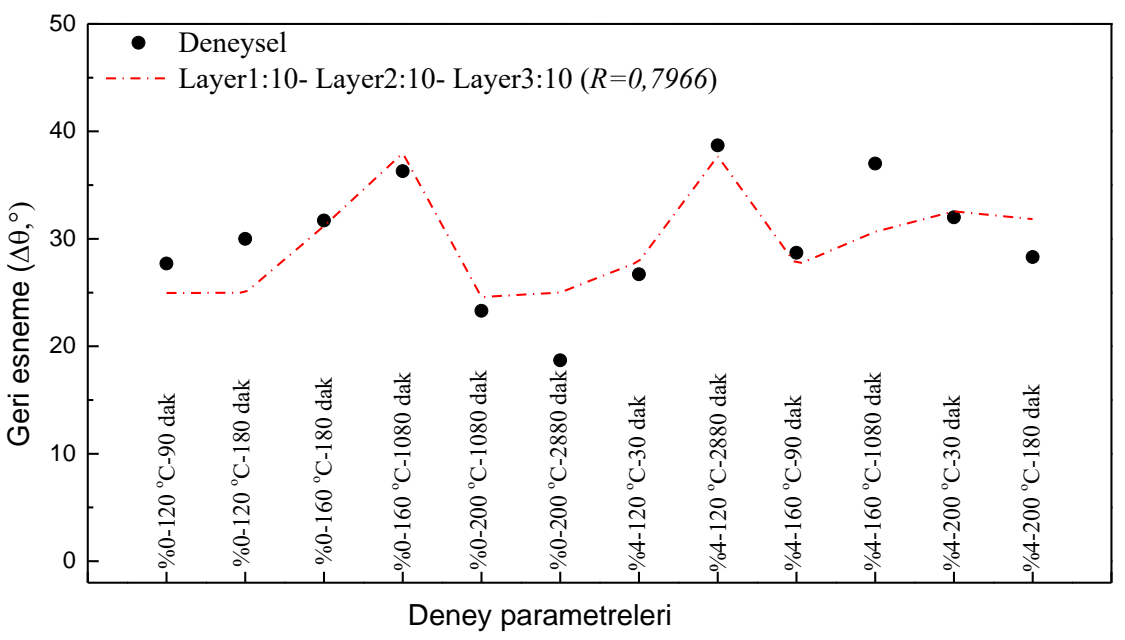

Şekil 9. Üç gizli katmanlı modelin tahminleri (18 eğitim verisi)

Şekil 10-12 arasındaki grafiklerde ise, eğitim için 24 veri kullanılarak geri kalan 6 verinin tahmini yaptırılmıştır. Şekil 10.'da, farklı nöron sayılarının tahmin üzerindeki etkisi verilmiştir. Bu modelde; nöron sayısı 10-15 olduğunda birbirine yakın korelasyon sonuçları elde edilirken, 20 olduğunda deneysel veriye daha yakın korelasyon sonucu elde edilmiştir. 18 eğitim verisi ile karşılaştırıldığında (Şekil 5), daha fazla eğitim verisinin deneysel sonuçlara daha yakın tahminler olduğu görülmüştür.

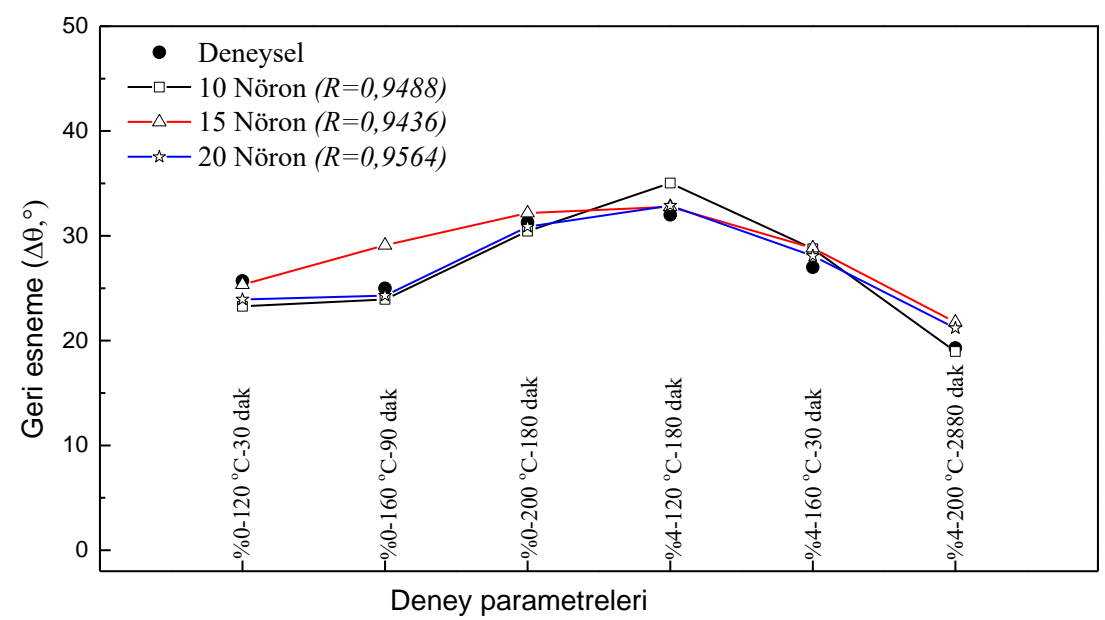

Şekil 10. Bir gizli katmanlı modelde nöron sayısının etkisi (24 eğitim verisi)

Şekil 11.'de, iki gizli katmanlı farklı nöron sayısına sahip model sonuçları görülmektedir (Model 1layer 1: 20 nöron, Layer 2: 10 nöron; Model 2- layer 1: 10 nöron, Layer 2: 10 nöron). Burada Model 2'nin daha yüksek korelasyon katsayısına sahip olduğu görülmektedir. Şekil 7 ile karşılaştırıldığında (18 eğitim verisi) daha fazla eğitim verisinin, deneysel sonuçlara daha yakın tahminler yaptığı görülmektedir. 


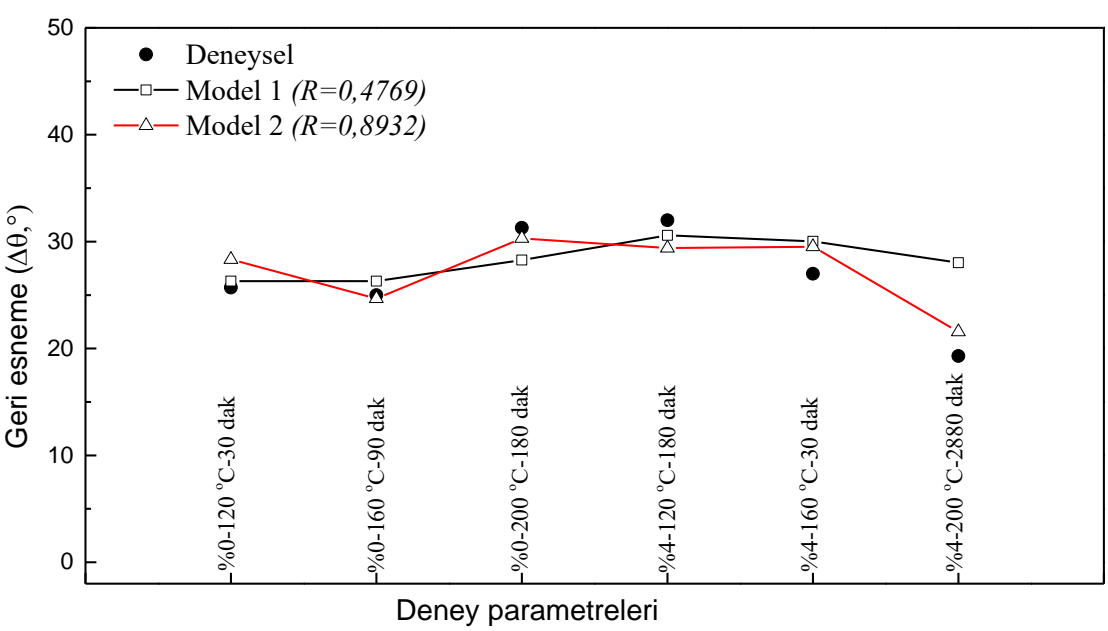

Şekil 11. İki gizli katmanlı modelde nöron sayısının etkisi (24 eğitim verisi)

Şekil 12.'de, üç gizli katmanlı sabit nöron sayılı bir katmanın tahmin sonuçları görülmektedir. Korelasyon sonucuna bakıldığında oldukça başarılı bir tahmin gerçekleştiği görülmektedir. Şekil 9 ile kıyaslandığında (18 eğitim verisi), daha fazla eğitim verisinin daha başarılı sonuçlar verdiği bu model içinde görülmektedir.

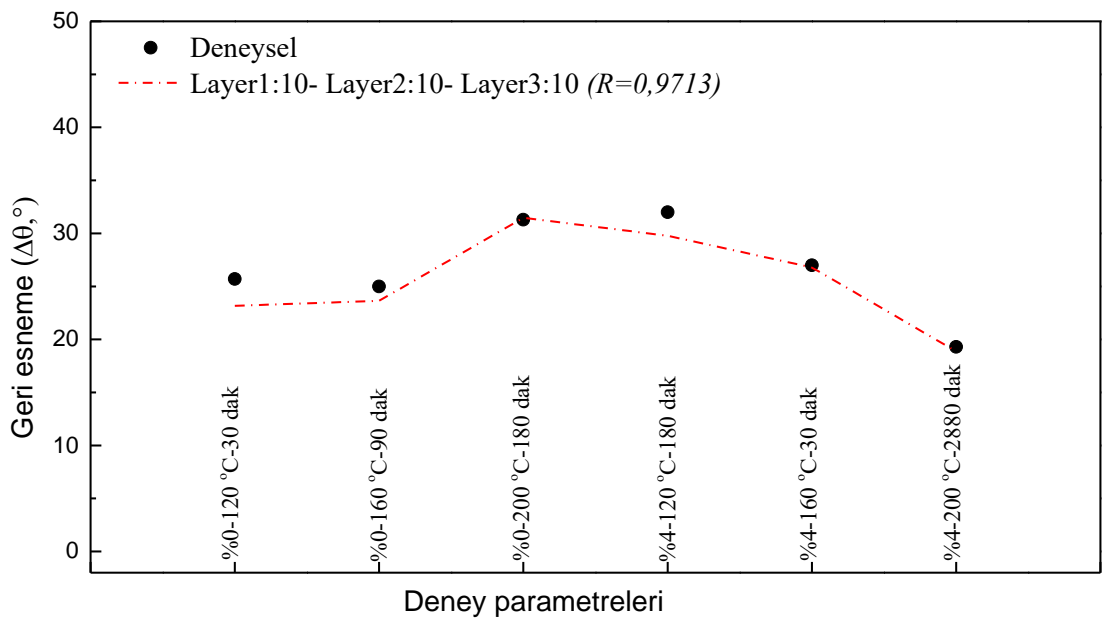

Şekil 12. Üç gizli katmanlı modelde nöron sayısının etkisi (24 eğitim verisi)

\section{B. Regresyon Model Denklemi ve Sonuçları}

Regresyon modeli ile geri esneme, ön gerinme, yaşlandırma süresi, sıcaklığı, akma ve çekme mukavemetlerinin arasındaki ilişkinin matematiksel ifadesi çıkartılmıştır. Bilindiği üzere Regresyon analizi, aralarında ilișki bulunan değişkenlerin bağımlı ve bağımsız olarak ayrıldıktan sonra, aralarındaki matematiksel bir eşitlik ile açıklanması işlemidir [24]. Regresyon modelinin, YSA modelleri ile kıyaslama yapılabilmesi için hem 18 hem de 24 deneysel veri kullanılarak 2 ve 3 numaralı denklemler elde edilmiştir. Tablo 1.'de 2 ve 3 numaralı denklemlerden elde edilen katsayılar verilmiştir. ANOVA analizine göre bu tablodaki dikkat çeken sonuç, akma mukavemetinin geri esnemeyi pozitif yönde etkilediğidir (0,079 değeri). Yani, akma mukavemetindeki her $1 \mathrm{MPa}$ değeri geri esnemeyi 0,079 derece artırdığı yorumu yapılabilir. Negatif değerlerin ise, geri esnemeyi azaltıcı etkisi olduğu söylemektedir. Akma ve çekme mukavemetleri arasında yapılan ANOVA analiz sonuçlarına göre akma mukavemetinde korelasyon katsayısı 0,981 iken; çekme mukavemetinde 
BȘEÜ Fen Bilimleri Dergisi

6 (2), 433-446, 2019
BSEU Journal of Science DOI: 10.35193/bseufbd.620010

0,736 olarak bulunmuştur (Şekil 14). Bu sonuçlara göre de, geri esneme üzerinde akma mukavemeti daha etkilidir.
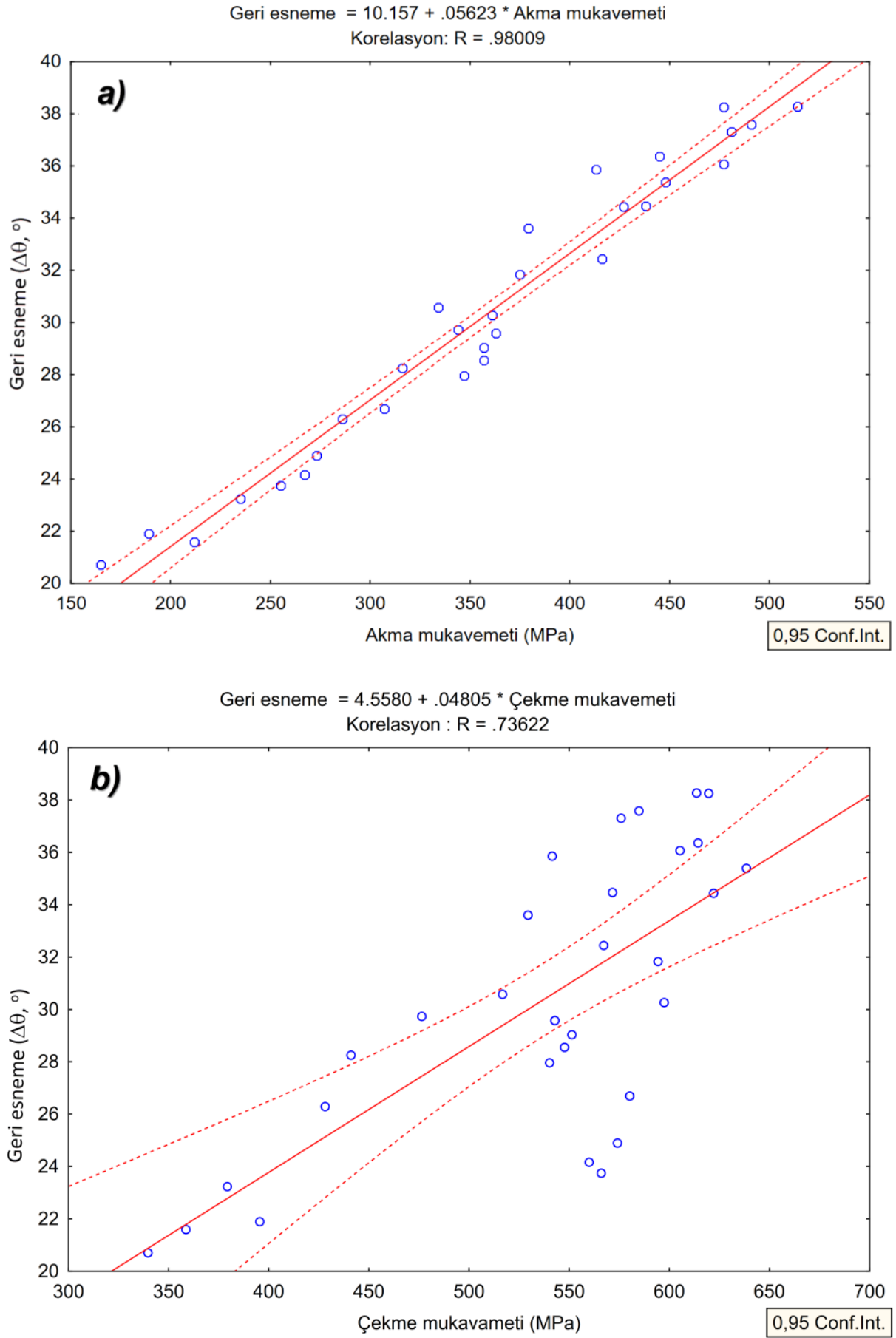

Şekil 14. a) Akma, b) Çekme mukavemetinin geri esneme üzerindeki etkisi

$$
R_{1}=\alpha+\text { Akma }^{*} \alpha_{1}+\text { Çekme }^{*} \alpha_{2}+\text { Yaş. Süresi } * \alpha_{3}+\text { Yaş. Sicaklı̆̆l } * \alpha_{4}+\ddot{\text { Ongerilme }} * \alpha_{5}
$$




$$
R_{2}=\alpha+\text { Akma }^{*} \alpha_{1}+\text { Çekme }^{*} \alpha_{2}+\text { Yaş. Süresi } * \alpha_{3}+\text { Yaş. Slcaklı̆̆g } * \alpha_{4}+\text { Öngerilme } * \alpha_{5}
$$

Tablo 1. Regresyon modeli katsayıları

\begin{tabular}{ccc}
\hline Katsayı & R1 model & R2 model \\
\hline$\alpha$ & 35,86 & 6,431 \\
$\alpha 1$ & 0,079 & 0,062 \\
$\alpha 2$ & $-0,049$ & $-0,004$ \\
$\alpha 3$ & 0,0 & 0,0 \\
$\alpha 4$ & $-0,031$ & 0,026 \\
$\alpha 5$ & $-1,152$ & $-0,227$ \\
\hline
\end{tabular}

Şekil 15.'de, 18 eğitim verisi kullanılarak elde edilen matematiksel denklemin tahmini görülmektedir. Korelasyon değeri 0,921 olarak hesaplanmıştır. Bir gizli katmanlı ve 15 nörona sahip YSA modelinin Regresyon modelinden daha iyi tahminde bulunduğu görülmüştür. YSA'da sonuca yaklaşmak için birçok etken parametreler bulunurken, regresyon modelinde yoktur.

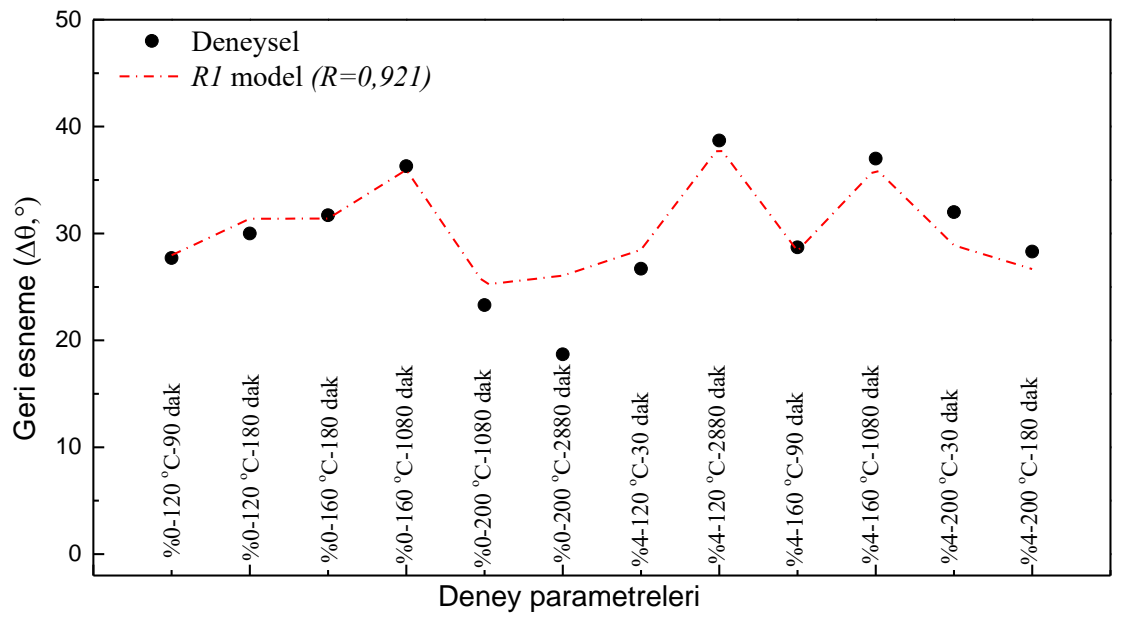

Şekil 15. 18 eğitim verisinde Regresyon model tahmini

Şekil 16.'da, 24 eğitim verisi kullanılarak elde edilen matematiksel denklemin tahmin değerleri görülmektedir. Regresyon modellerinde de eğitim verisi sayısı arttıkça, korelasyon katsayısı yükselmektedir. Bu regresyon modeli ile YSA karşılaştırıldığında, yine YSA modellerinin, deneysel sonuçlara daha yakın taminler yaptığı görülmüştür. Aynı şekilde YSA işleminde tahmin performansını artırmak için çeşitli yöntemler kullanılırken, Regresyon denkleminde ise bu yoktur. 


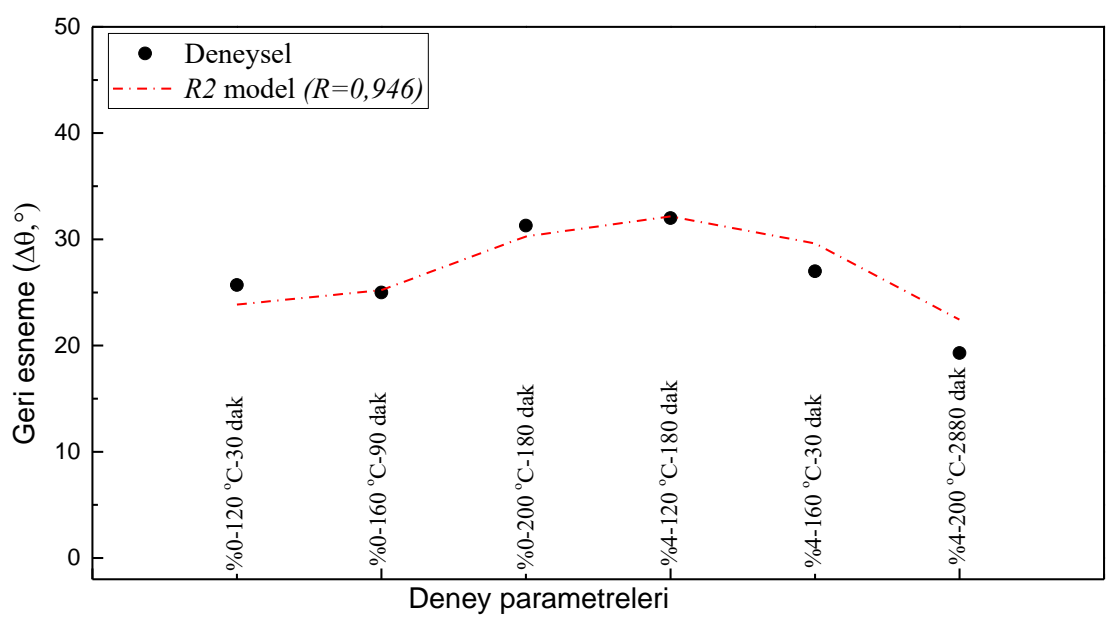

Şekil 16. 24 eğitim verisinde regresyon model tahmini

\section{SONUÇLAR}

$\mathrm{Bu}$ çalışma kapsamında imalat endüstrisinde önemli problemlerin başında gelen geri esneme davranışının tahmin edilmesinde YSA ve Regresyon denklemlerinin kullanılması araştırılmıştır. Yapılan çalışmalar sonucunda;

- YSA modellerinde farklı modeller oluşturulmuş ve tahmin üzerindeki etken parametreler incelenmiştir. Nöron sayısı deneme yanılma yolu ile bulunmaktadır. Nöron sayısı tahmin üzerinde etkilidir.

- Gizli katman sayısı; tahminler üzerinde etkili olup, yine seçilecek nöron sayısı ile ilişkilidir.

- Eğitim verisinin fazla olması, her iki yöntemde de tahmin performansını yükseltmektedir.

- Regresyon denklemlerinde model tahminini yükseltmek için bir parametre olmamasına karşın, YSA modelinde birçok parametre ile bu sağlanabilmektedir.

- YSA modelleri regresyon modellerine göre daha başarılı tahminler yapmaktadır. fazla etkilidir.

- ANOVA analizine göre geri esneme üzerinde akma mukavemeti, çekme mukavemetinden daha

- Elde edilen sonuçlara göre yaşlandırma işleminde YSA ile başarılı geri esneme tahminleri yapılabilir. Fakat, katman ve nöron sayısı parametrelerinin doğru olarak ayarlanması sistemin başarı oranını artıracaktır.

\section{TEŞEKKÜR}

Bu çalışmada yararlanılan veriler, Ahi Evran Üniversitesi Bilimsel Araştırma Projeleri Koordinasyon Birimi'nce desteklenen MMF.A3.17.001 numaralı Projesinden yayınlanan Effects of Aging Temperature, Time, and Pre-Strain on Mechanical Properties of AA7075 (http://dx.doi.org/10.1590/1980-5373-MR-2019-0006) başlıklı çalışmadan alınmıştır. Desteklerinden dolayı Bilimsel Araştırma Projeleri Koordinasyon Birimi’ne teşekkürlerimi sunarım. 


\section{KAYNAKLAR}

[1] Öztemel, E. (2003). Yapay sinir ağlari. Türkiye, 44.

[2] Hamzaçebi, C. \& Kutay, F. (2004). Yapay sinir ağlari ile Türkiye elektrik enerjisi tüketiminin 2010 yılına kadar tahmini. Gazi Üniversitesi Mühendislik-Mimarlık Fakültesi Dergisi, 19 (3), 227-233.

[3] Ataseven, B. (2014). Yapay sinir ağları ile öngörü modellemesi. Marmara Üniversitesi, 10 (39), 101-115.

[4] Uğur, A. \& Kınacı, A. C. (2006). Yapay zeka teknikleri ve yapay sinir ağları kullanılarak web sayfalarının sinıflandırılması. XI. Türkiye'de Internet Konferansı Bildirileri, 362.

[5] Kutlu, B. \& Badur, B. (2009). Yapay sinir ağları ile borsa endeksi tahmini. Yönetim Dergisi, 20 (63), 4540.

[6] Yıldıran, A. \& Kandemir, S. Y. (2018). Yağış Miktarının Yapay Sinir Ağları ile Tahmini. Bilecik Şeyh Edebali Üniversitesi Fen Bilimleri Dergisi, 5 (2), 97-104.

[7] Güngör, O. (2019). Güneș Panellerinde Cuk Dönüștürücü Tabanlı Değişken Sartlar Altında PNO, BM ve YSA Algoritmalarının Karşılaştırmalı Performans Analizi. Bilecik Şeyh Edebali Üniversitesi Fen Bilimleri Dergisi, 6 (1), 66-76.

[8] Kubat, C. \& Kiraz, A. (2012). Yapay zeka kullanılarak sanal laboratuar tasarımında çekme testinin modellenmesi. Gazi Üniversitesi Mühendislik-Mimarlık Fakültesi Dergisi, 27 (1), 205-210.

[9] Toktaş, İ. \& Aktürk, N. (2011). Yapay sinir ağları tabanlı silindirik düz dişli çark tasarımı. Pamukkale Üniversitesi Mühendislik Bilimleri Dergisi, 13 (3), 387-395.

[10] Ergür, H. S. (2007). Aşındırıcı su jetinin teorik analizi ve yapay sinir ağı yöntemiyle modellenmesi. Eskişehir Osmangazi Üniversitesi Mühendislik ve Mimarlık Fakültesi Dergisi, 22 (2), 179-197.

[11] Bilgiç, H. H., Yağlı, H., Koç, A., \& Yapıcı, A. (2016). Deneysel bir organik rankine çevriminde yapay sinir ağları (YSA) yardımıyla güç tahmini. Selçuk Üniversitesi Mühendislik, Bilim Ve Teknoloji Dergisi, 4 (1), 7-17.

[12] Kılıç, S., Kacar, İ., Öztürk, F., Şahin, M., \& Erdem, O. (2019). AA7075 Yaşlandırılmasında Farklı Ön Gerinmelerin Mekanik Özelliklere Etkilerinin İncelenmesi. International Journal of Advances in Engineering and Pure Sciences, 31 23-32.

[13] Kılıç, S., Öztürk, F., \& Toros, S. (2009). DP 800 çeliğinin Mekanik Özelliklerinin ve Geri Esneme Davranışının İncelenmesi. Makina Tasarım ve İmalat Dergisi, 11 (1), 40-45.

[14] Ozturk, F., Toros, S., Kilic, S., \& Bas, M. H. (2009). Effects of cold and warm temperatures on springback of aluminium-magnesium alloy 5083-H111. Proceedings of the Institution of Mechanical Engineers, Part B: Journal of Engineering Manufacture, 223 (4), 427-431.

[15] Ozturk, F., Toros, S., \& Kilic, S. (2009). Tensile and spring-back behavior of DP600 advanced high strength steel at warm temperatures. Journal of Iron and Steel Research, International, 16 (6), 41-46.

[16] Inamdar, M., Date, P. P., Narasimhan, K., Maiti, S. K., \& Singh, U. P. (2000). Development of an Artificial Neural Network to Predict Springback in Air Vee Bending. The International Journal of Advanced Manufacturing Technology, 16 (5), 376-381.

[17] Kazan, R., Fırat, M., \& Tiryaki, A. E. (2009). Prediction of springback in wipe-bending process of sheet metal using neural network. Materials \& Design, 30 (2), 418-423. 
[18] Bozdemir, M. \& Gulcu, M. (2008). Artificial neural network analysis of springback in V bending. Journal of Applied Sciences, 8 (17), 3038-3043.

[19] Liu, W., Liu, Q., Ruan, F., Liang, Z., \& Qiu, H. (2007). Springback prediction for sheet metal forming based on GA-ANN technology. Journal of Materials Processing Technology, 187-188 227-231.

[20] Zhang, J., Zhang, F., Ruan, J., \& He, K. (2018). Study on springback behavior of carbon steel during single-point dieless forming based on neural network method. Materials Science and Engineering, 397 (1), 012065 .

[21] Kilic, S., Kacar, I., Sahin, M., Ozturk, F., \& Erdem, O. (2019). Effects of Aging Temperature, Time, and Pre-Strain on Mechanical Properties of AA7075. Materials Research, 5 (22), 1-15.

[22] Çavuşlu, M. A., Becerikli, Y., \& Karakuzu, C. (2012). Levenberg-Marquardt algoritması ile YSA eğitiminin donanımsal gerçeklenmesi. Türkiye Bilişim Vakfı Bilgisayar Bilimleri ve Mühendisliği Dergisi, 5 (1), 1-7.

[23] Office, M. (2019). Korelasyon işlevi. https://support.office.com/tr-tr/article/korelasyon-i\%C5\%9Flevi995dcef7-0c0a-4bed-a3fb-239d7b68ca92, 01.05.2019.

[24] Köklü, N., Büyüköztürk, Ş., \& Çokluk-Bökeoğlu, Ö. (2006). Sosyal Bilimler İçin İstatistik . Ankara, 264. 